\title{
Age and Sex Identification Using Multi-slice Computed Tomography of the Last Thoracic Vertebrae of an Egyptian Sample
}

Ramadan N*, Abd El-Salam MH, Hanon AF, El-Sayed NF and Al-Amir AY

Faculty of Medicine, Cairo University Kasr Alainy, Cairo, Egypt

*Corresponding author: Ramadan N, Faculty of Medicine, Cairo University Kasr Alainy, Cairo, Egypt, Tel: 201066866336; E-mail: drnazihramadan@kasralainy.edu.eg Received date: July 15, 2017; Accepted date: July 27, 2017; Published date: August 10, 2017

Copyright: (c) 2017 Ramadan N, et al. This is an open-access article distributed under the terms of the Creative Commons Attribution License, which permits unrestricted use, distribution, and reproduction in any medium, provided the original author and source are credited.

\begin{abstract}
Introduction: Accurate sex estimation plays a very important role in determining the identity of unknown individuals. Age determination also has become increasingly important in forensic science for both living and remains. Vertebrae are one of the least studied bones for age and sex identification; however, its presence at a death scene is the most common of all. The $12^{\text {th }}$ thoracic vertebra (T12) is easily identifiable in a disarticulated skeleton, due to its unique morphology. Identification depending on radiological techniques is an emerging valuable tool in forensic science field.
\end{abstract}

Methodology: The study was conducted on 123 Egyptian patients; 61 males and 62 females and the age range was from 10 to 64 years. The subjects used in this study were patients who had a need for Computer Tomography (CT) scan of the abdomen for several medical reasons in the Radiology Departments of Cairo University and the CT was done for them after giving informed consent. None of the vertebrae used possessed any pathological condition and vertebrae with moderate to severe degenerative changes and osteophyte formation were excluded from this study. Fifteen linear measurements were taken for T12 thoracic vertebrae. All the procedures for this study were approved by the ethical committee of faculty of medicine, Cairo University. Microsoft excel 2010 was used for data entry and the statistical package for social science (SPSS version 21) was used for data analysis.

Results: Males were statistically significant larger than females in all measurements of T12, and sex was identified from $\mathrm{T} 12$ at accuracy rate $88.6 \%$. In addition, there was significant positive correlation between age and most of measurements, however, this correlation wasn't strong.

Conclusion: Computed tomography of T12 vertebrae is a useful tool for sex and age Identification of unknown; however, further studies are needed for proper evaluation of its role on age estimation.

Keywords Computed tomography; Egyptians; $12^{\text {th }}$ thoracic vertebrae; Age; Sex

\section{Introduction}

Personal identification is a main task in forensic practice. Determination of sex, age, stature and ancestry, which is known as biological profile, decrease the possible victim matches in the forensic investigation process and therefore provide useful clues in personal identification [1].

Sex identification is an important starting point in developing a biological profile for human skeletal remains as it reduces the number of possible matches by $50 \%$ [2]. Age estimation is also important in both anthropology and forensic medicine [3].

When complete skeleton is available, the pelvis and skull are the most reliable indicators of sex estimation [4]. However, in several situations, especially when post-mortem interval increases, the human skeleton became porous, fragmented or destroyed [5]. So it is essential to develop other methods for sex identification using a wide range of skeletal elements [6].

Many previous studies reported sexual dimorphism of different vertebrae from cervical, thoracic, and lumbar regions of the spinal column [7]. In addition, morphological changes of the vertebrae have been shown to be useful in understanding ageing patterns [8].

The $12^{\text {th }}$ thoracic vertebra (T12) is easily identifiable in a disarticulated skeleton, due to its unique morphology. Its place as a transitional vertebra results in the morphological characteristics between both thoracic and lumbar vertebrae [9].

Recently, Postmortem Computed Tomographies (PMCT) becomes a valuable tool in forensic practice; due to its effectiveness in visualization of osseous structures, it can help forensic anthropologists to can collect data for estimation of biological profiles using the skeleton [10].

Only few studies that tested the role MSCT of the $12^{\text {th }}$ thoracic vertebrae (T12) in sex identification, however, this is the first study to use MSCT for evaluation of the role of T12 measurements in age estimation.

The aim of the present study is to develop population specific parameters for sex and age determination based on the $12^{\text {th }}$ thoracic vertebra measurements among Egyptians, a population that has not been represented so far in the existing forensic anthropology population databases. 
Citation: Ramadan N, El-Salam MHA, Hanoon AM, El-Sayed NF, Al-Amir AY (2017) Age and Sex Identification Using Multi-slice Computed Tomography of the Last Thoracic Vertebrae of an Egyptian Sample. J Forensic Res 8: 386. doi:10.4172/2157-7145.1000386

Page 2 of 6

\section{Subjects and Methods}

\section{Subjects}

All the procedures for this study were approved by the ethical committee of faculty of medicine, Cairo University. The study was conducted on 123 Egyptian patients; 61 males (ages ranged from 10 to 64 years) and 62 females (ages ranged from 10 to 60 years). The subjects used in this study were patients who had a need for computer tomography (CT) scan of the abdomen for several medical reasons in the Radiology Departments of Cairo University and the CT was done for them after giving informed consent. None of the vertebrae used possessed any pathological condition and vertebrae with moderate to severe degenerative changes and osteophyte formation were excluded from this study

\section{Methods}

Computer tomographic (CT) scanning was performed using a helical CT scanner imaging machine (SOMATOM emotion 16 slice 78830, Siemens, Germany). The patients lay supine on the scanner. The scanning procedure was performed to acquire $1.5 \mathrm{~mm}$ slices width; bone window and sharpness B70 for optimum visualization using the software program analyze (Syngo VB 42). Most of images were maximum intensity projection (MIP) images to minimize errors of measurements. The protocol used was identical for all patients to avoid technical variations in measurements. Measurements were taken using the calibrated ruler of the system and are approximated to the nearest $0.1 \mathrm{~mm}$. Fifteen linear measurements were taken for T12 thoracic vertebrae as described in Table 1 and Figure 1 at the workstation by senior radiologist.

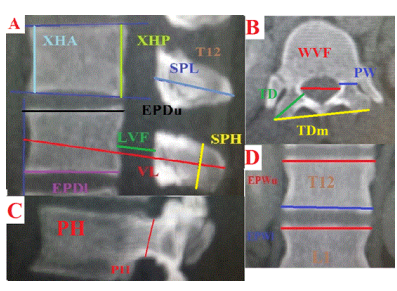

Figure 1: Measurements taken from the $12^{\text {th }}$ thoracic vertebrae. A: Sagittal plane, B: Axial plane, C: Sagittal plane at level of pedicle, and D: Coronal plane.

\section{Statistical analysis}

Microsoft excel 2010 was used for data entry and the statistical package for social science (SPSS version 21) was used for data analysis. Simple descriptive statistics (arithmetic mean and standard deviation) used for summary of quantitative data and frequencies used for qualitative data. T-independent test was used to compare normally distributed qualitative data. Pearson correlation was used to compare normally distributed quantitative data and Pearson correlation coefficient describes the direction (either positive or negative) and the power of correlation $(<0.5$ weak correlation) (between 0.5 and 0.7 moderate correlation) (>0.7 strong correlation). Those factors that demonstrated significant association with age in bivariate analysis $(\mathrm{P}<0.05)$ were included in linear regression models, and those factors that demonstrated significant association with sex in bivariate analysis $(\mathrm{P}<0.05)$ were included in stepwise discriminant function analysis models [11].

\begin{tabular}{|c|c|c|}
\hline Measurement & Description & Image \\
\hline Upper end plate depth (EPDu) & Distance from the anterior edge to the posterior edge of the upper endplate & Sagittal MIP \\
\hline Lower end plate depth (EPDI) & Distance from the anterior edge to the posterior edge of the lower endplate & Sagittal MIP \\
\hline Upper end plate width (EPWu) & Distance between the most lateral edges of the upper endplate & Coronal MIP \\
\hline Lower end plate width (EPWI) & Distance between the most lateral edges of the lower endplate & Coronal MIP \\
\hline $\begin{array}{l}\text { Maximum height of anterior vertebral } \\
\text { body }(\mathrm{XHA})\end{array}$ & Distance between the upper and lower most points of the anterior cortex of the vertebral body & Sagittal MIP \\
\hline $\begin{array}{l}\text { Maximum height of posterior } \\
\text { vertebral body }(\mathrm{XHP})\end{array}$ & Distance between the upper and lower most points of the posterior cortex of the vertebral body & Sagittal MIP \\
\hline $\begin{array}{l}\text { Length of the vertebral foramen } \\
\text { (LVF) }\end{array}$ & $\begin{array}{l}\text { The sagittal internal length of vertebral foramen between the posterior aspect of the vertebral body and the } \\
\text { anterior aspect of the spinous process }\end{array}$ & Sagittal MIP \\
\hline $\begin{array}{l}\text { Maximum width of the vertebral } \\
\text { foramen (WFV) }\end{array}$ & The maximum internal side to side width of the vertebral foramen & Axial \\
\hline Spinal process length (SPL) & From inner posterior border of the vertebral foramen to the most posterior edge of the spinous process & Sagittal MIP \\
\hline Spinal process height (SPH) & $\begin{array}{l}\text { Distance from the superior border to the inferior border at junction of the middle and posterior } 1 / 3 \text { s of the } \\
\text { spinous process }\end{array}$ & Sagittal MIP \\
\hline Pedicle height $(\mathrm{PH})$ & Distance between the superior and inferior borders of the left pedicle & Sagittal MIP \\
\hline Pedicle width (PW) & Distance between the lateral and medial edges of the left pedicle & Axial \\
\hline Vertebral length (VL) & $\begin{array}{l}\text { Distance from the center of a line touching the anterior edge of vertebral body to the posterior edge of spinous } \\
\text { process }\end{array}$ & Sagittal MIP \\
\hline
\end{tabular}


Citation: Ramadan N, El-Salam MHA, Hanoon AM, El-Sayed NF, Al-Amir AY (2017) Age and Sex Identification Using Multi-slice Computed Tomography of the Last Thoracic Vertebrae of an Egyptian Sample. J Forensic Res 8: 386. doi:10.4172/2157-7145.1000386

Page 3 of 6

\begin{tabular}{|l|l|l|}
\hline Transverse process diameter (TD) & The distance from the tip of the right transverse process to the inner border of the lamina \\
\hline Transverse process distance (TDm) & Maximum distance between the lateral edges of both transverse processes \\
\hline $\begin{array}{l}\text { EPDu, EPDI, XHA, XHP, LVF, SPL, SPH and VL were taken in sagittal plane after images were adjusted using axial and coronal images to acquire the appropriate } \\
\text { view of the center of the T12 and L1, while PH was taken from sagittal MIP images after images was adjusted using axial plan to acquire the appropriate view of the } \\
\text { center of right pedicle. EPWu and EPWI were taken from coronal MIP images after being adjusted using axial and sagittal planes acquire the appropriate view of the } \\
\text { center of the body of T12 and L1. WVF, PW, TD and TDm were taken in axial plane that were adjusted by at level bisecting the pedicle in sagittal plane }\end{array}$ \\
\hline
\end{tabular}

Table 1: Nomenclature of the different measurements from the last thoracic vertebrae.

\section{Results}

The results of descriptive statistics showed that males displayed larger mean values than females for all measured variables of $12^{\text {th }}$ thoracic vertebrae (Table 2). Most of the dimensions differed highly significantly $(\mathrm{P}<0.001)$ between sexes.

\begin{tabular}{|c|c|c|c|c|c|c|c|c|c|}
\hline & \multicolumn{4}{|c|}{ Males } & \multicolumn{4}{|c|}{ Females } & \multirow{3}{*}{$\begin{array}{l}\text { P. value } \\
0.000^{* *}\end{array}$} \\
\hline & Min. & Max. & Mean & S.D. & Min. & Max. & Mean & S.D. & \\
\hline EPDu & 22 & 41 & 31.9 & 3.9 & 22.5 & 32.2 & 28.2 & 2.1 & \\
\hline EPDI & 22.6 & 38.6 & 31.9 & 3.3 & 21.8 & 32.5 & 27.9 & 2.3 & $0.000^{* *}$ \\
\hline XHA & 15 & 29.2 & 24.2 & 3.1 & 16.2 & 26 & 22.8 & 1.8 & $0.000^{* *}$ \\
\hline XHP & 16 & 34 & 27.2 & 3.5 & 16 & 28.3 & 24.7 & 1.9 & $0.000^{* *}$ \\
\hline LVF & 11 & 18.4 & 14.4 & 1.6 & 10 & 17 & 13.4 & 1.6 & $0.001^{*}$ \\
\hline SPL & 16 & 37.6 & 28.8 & 4.6 & 15 & 36 & 26.3 & 3.9 & $0.002^{*}$ \\
\hline SPH & 10 & 29 & 17.8 & 4.2 & 10 & 21.7 & 16.3 & 2.9 & $0.023^{*}$ \\
\hline VL & 54 & 83.5 & 74.3 & 6.6 & 54.5 & 74 & 67 & 4.1 & $0.000^{* *}$ \\
\hline PH & 10 & 21.5 & 17.2 & 2.2 & 11 & 17 & 14.9 & 1.3 & $0.000^{* *}$ \\
\hline EPWu & 28.5 & 50 & 42.4 & 4.6 & 30 & 45 & 36.6 & 2.9 & $0.000^{* *}$ \\
\hline EPWI & 31 & 57 & 45.2 & 4.9 & 31 & 43 & 38.5 & 2.7 & $0.000^{* *}$ \\
\hline WVF & 19 & 28 & 23.9 & 2.3 & 17.6 & 28 & 22.2 & 2.1 & $0.000^{* *}$ \\
\hline TD & 11.7 & 26.2 & 18.2 & 2.8 & 11.2 & 20 & 15.9 & 1.9 & $0.000^{* *}$ \\
\hline TDM & 32.6 & 59 & 46.3 & 6.6 & 30 & 50 & 41.1 & 4.1 & $0.000^{* *}$ \\
\hline PW & 6.6 & 14 & 10.2 & 1.7 & 5 & 11 & 8.6 & 1.4 & $0.000^{* *}$ \\
\hline
\end{tabular}

Table 2: Difference between males and females in measurements of $12^{\text {th }}$ thoracic vertebrae.

Stepwise discriminant function analysis showed that sex can be predicted from T12 measurements at accuracy rate $88.6 \%$ using the following equation:

$\mathrm{S}=0.187^{\star} \mathrm{EPDl}-0.271^{\star} \mathrm{XHP}+0.279^{\star} \mathrm{LVF}+0.229^{\star} \mathrm{EPWl}-12.660$
If the result of this equation less than the sectioning point (zero), the sex is female. If the result of this equation more than the sectioning point (zero), the sex is male. The Correct prediction rate (accuracy) of this equation is $88.6 \%$ (Table 3 ).

\begin{tabular}{|l|l|l|l|l|l|l|l|l|l|}
\hline & & \multicolumn{2}{|l|}{$\begin{array}{l}\text { Fisher's linear discriminant } \\
\text { function }\end{array}$} & $\begin{array}{l}\text { Unstandardized } \\
\text { Measurements }\end{array}$ & Group centroid & \multicolumn{2}{l|}{$\begin{array}{l}\text { Wilks' } \\
\text { Lambda }\end{array}$} & \multicolumn{2}{l|}{ Correct prediction rate } \\
\cline { 2 - 11 } & Males & females & males & females & male & female & overall & \\
\hline EPWI & 0.187 & 3.457 & 3.05 & 1.098 & -1.081 & 0.563 & $85.20 \%$ & $91.90 \%$ & $88.60 \%$ \\
\hline XHP & -0.271 & -0.212 & 0.378 & - & - & 0.52 & - & - & - \\
\hline
\end{tabular}


Citation: Ramadan N, El-Salam MHA, Hanoon AM, El-Sayed NF, Al-Amir AY (2017) Age and Sex Identification Using Multi-slice Computed Tomography of the Last Thoracic Vertebrae of an Egyptian Sample. J Forensic Res 8: 386. doi:10.4172/2157-7145.1000386

Page 4 of 6

\begin{tabular}{|l|l|l|l|l|l|l|l|l|l|}
\hline LVF & 0.279 & 7.006 & 6.398 & - & - & 0.503 & - & - & - \\
\hline EPDI & 0.229 & 1.45 & 0.952 & - & - & 0.488 & - & - \\
\hline Constant & -12.66 & -136.472 & -108.87 & - & - & - & - & - & - \\
\hline
\end{tabular}

Table 3: Unstandardized discriminate function equations and demarking points for predicting the sex of the $12^{\text {th }}$ thoracic vertebra when using one measurement.

Correlation studies were done and revealed the presence of significant positive correlation between age and all measurements of
T12 $(\mathrm{p}<0.05)$ except for LVF, PW, TD and TDm for which the correlation were not significant (Table 4$)$.

\begin{tabular}{|l|l|l|}
\hline Measurement & Pearson Correlation & P value \\
\hline EPDu & 0.335 & $0.000^{* *}$ \\
\hline EPDI & 0.282 & $0.002^{*}$ \\
\hline XHA & 0.409 & $0.000^{* *}$ \\
\hline XHP & 0.362 & $0.000^{* *}$ \\
\hline LVF & -0.001 & 0.993 \\
\hline SPL & 0.379 & $0.000^{*}$ \\
\hline SPH & 0.449 & $0.000^{* *}$ \\
\hline VL & 0.388 & $0.000^{* *}$ \\
\hline PH & 0.268 & $0.003^{*}$ \\
\hline EPWu & 0.38 & $0.000^{* *}$ \\
\hline EPWI & 0.364 & $0.000^{* *}$ \\
\hline WVF & 0.247 & $0.006^{*}$ \\
\hline TD & 0.044 & 0.628 \\
\hline TDm & 0.136 & 0.134 \\
\hline PW & 0.07 & 0.441 \\
\hline
\end{tabular}

Table 4: Correlation between age and measurements of T12.

In addition, Linear regression analysis of the significant measurements showed that age can be predicted from T12 using the following model: Age $=-10.685+1.752^{\star}$ XHA (the adjusted $R^{2}$ is 0.348 with the $\mathrm{R}^{2}=0.471$ ).

\section{Discussion}

In the current study, males displayed larger mean values than females for all measured variables of $12^{\text {th }}$ thoracic vertebrae and sex was predicted at accuracy rate $88.6 \%$. These results were in great accordance with previous studies $[2,12,13]$.

Badr and El Shafei [2] study on Egyptians concluded that most of T12 measurements were sexually dimorphic using multi-slice computed tomography (MSCT), with accuracy of $93.1 \%$. Hou et al. [13] also reported sexual dimorphism of all measurements of T12 of Chinese except LVF with accuracy rate of $94.2 \%$ using MSCT. In addition, $\mathrm{Yu}$ et al. [12] reported that there was statistical significant difference between males and females in most of measurements taken from T12 multi-slice computed tomography of Korean sample with accuracy rate $90 \%$.

Moreover, different studies as [7,14-16], approved the role of T12 measurements in sex determination, however, they took measurements from $\mathrm{T} 12$ real bone (Table 5).

There are many advantages for taking measurements from MSCT:

- It is an effective technique for depiction of osseous structures [17].

- The use of CT images increases accuracy and reproducibility over traditional metric analyses in a biological profile identification [18].

- Data treatment using appropriate software reduces errors associated with the location of the landmarks and the performance of the measurements [19].

- CT scans offer an easy way for data collection and storage to create databases for forensic anthropology studies [10]. 
Zech et al. [20] concluded that metric measurements based on CT images were very accurate and comparable to caliper measurements on real bones.

\begin{tabular}{|c|c|c|c|c|c|c|}
\hline Author & Year & Population & Measurements & Most accurate & Method & Accuracy \\
\hline Current study & 2017 & Egyptians & 15 & EPDI, LVF, XHP, EPWI & MSCT & $88.60 \%$ \\
\hline Badr and El Shafei & 2015 & Egyptians & $24+$ ratios(including ours) & EPDI, EPWu & MSCT & $93.10 \%$ \\
\hline Amores et al. & 2014 & Spanish & 8 (4 in our study) & EPDI & Real bone & $80.20 \%$ \\
\hline Gambaro & 2013 & Greek & $16(12$ in our study) & VLi, EPDI & Real bone & $79 \%$ \\
\hline Hou et al. & 2012 & Chinese & $30+$ ratios(including ours) & EPDI & MSCT & $94.20 \%$ \\
\hline \multirow[t]{2}{*}{ Yu et al. } & 2008 & Korean & $33+$ ratios(including ours) & EPWu, EPWI, & MSCT & $90 \%$ \\
\hline & \multirow[b]{2}{*}{2005} & \multirow[b]{2}{*}{ Americans } & & \multirow[b]{2}{*}{ EPD, EPW } & \multirow[b]{2}{*}{ Real bone } & $86.60 \%$ \\
\hline Pastor & & & 14 (9 in our study) & & & $88.90 \%$ \\
\hline Jankauskas & 1994 & Lithuanian & \multicolumn{2}{|l|}{ XHA, XHP, TBD } & \multicolumn{2}{|l|}{ Real bone } \\
\hline
\end{tabular}

Table 5: Studies approved the role of measurements of last thoracic vertebrae in sex identification.

Although few studies used MSCT in sex identification from T12, no previous study, to my extent of knowledge, tried to evaluate the role of MSCT in age estimation from measurements of T12. Even for other vertebrae, Only few studies [21,22] that tested the role of aging on vertebrae and they used real bone not imaging.

The current study showed that there was significant positive correlation between age and all measurements of T12 except LVF, PW, TD and, TDm. Unfortunately, these correlations weren't strong; mostly because the role of degenerative changes and osteophyte formation was excluded from this study.

Ruhli et al. [21] on modern Swiss and historic European real bone samples, showed that after exclusion of degenerative changes, there was significant moderate positive correlation between age and sagittal body diameter and significant weak positive correlation between age and transverse body diameter of the 7 th cervical vertebrae (C7) in males of both samples, while for females there was no correlation between age and any measurement in modern sample and only weak correlation between age and sagittal body diameter of $\mathrm{C} 7$ in historic sample. Also for the first thoracic vertebrae (T1) there was significant moderate positive correlation between age and sagittal body diameter and significant weak positive correlation between age and transverse body diameter in males only of modern sample but for historic sample there was significant weak positive correlation between age and sagittal body diameter for both males and females. For the first lumber vertebrae (L1) there was weak significant correlation for males only between age and endplate width \& pedicle height in modern sample and between age and endplate depth in historic sample.

Furthermore, Liguoro et al. [23] on real bone vertebrae concluded that sagittal body diameter (SBD) of all cervical vertebrae (from C2 to C7) were the best age indicator. Different researchers [8,14,24-26] proved that there was a significant correlation between age and some vertebral measurements due to degenerative changes of the vertebrae; All these studies conducted on real bone vertebrae.

In addition, different authors [27-37] proved strong positive correlation between age and vertebral body height (anterior, posterior and middle) on lateral radiography of cervical vertebrae or vertebral volume on CT of cervical vertebrae, however, these studies were conducted on young ages $<18$ years to identify cervical vertebral maturation as a method of age estimation in juveniles which was different from this study.

In contrast, Taitz [38] found that no relationship between aging and the size of the vertebral foramen diameters (LVF and WVF) in males or females, while Ishikawa et al. [39] found that the WVF diameter decreased with age in males and females, and these studies were on real bone not imaging.

Finally, MSCT of the last thoracic vertebrae is a useful tool for sex identification especially in cases of mass disasters where other bones may be destroyed, with further studies needed to evaluate its role in age determination.

\section{References}

1. Amitava P, Sujaya D, Sengupta P, Maity P, Dhara C (2016) Estimation of stature from hand dimensions in Bengali population, West Bengal, India. Egypt J Forensic Sci 6: 90-98.

2. Badr El, El Shafei MM (2015) Sex determination using anthropometric measurements from multi-slice computed tomography of the 12th thoracic and the first lumbar vertebrae among adult Egyptians. Egypt J Forensic Sci 5: 82-89.

3. Jagannathan N, Neelakantan P, Thiruvengadam C, Ramani P (2011) Age estimation in an Indian population using pulp/tooth volume ratio of mandibular canines obtained from cone beam computed tomography. J Forensic Odontostomatol 29: 1-6.

4. Marlow E (2016) Metric sex estimation of ancient Egyptian skeletal remains. Part I: Testing of published methods. Bioarchaeology of the Near East 10: 1-25.

5. Cowal LS, Pastor RF (2008) Dimensional variation in the proximal ulna: evaluation of a metric method for sex assessment. Am J Phys Anthropol 135: 469-478.

6. Marlow EJ, Pastor RF (2011) Sex determination using the second cervical vertebra-A test of the method. J Forensic Sci 56: 165-9.

7. Amores A, Botella MC, Alemán I (2014) Sexual dimorphism in the 7th cervical and 12th thoracic vertebrae from a Mediterranean population. J Forensic Sci 59:301-305. 
Citation: Ramadan N, El-Salam MHA, Hanoon AM, El-Sayed NF, Al-Amir AY (2017) Age and Sex Identification Using Multi-slice Computed Tomography of the Last Thoracic Vertebrae of an Egyptian Sample. J Forensic Res 8: 386. doi:10.4172/2157-7145.1000386

Page 6 of 6

8. Kacar E, Unlu E, Beker-Acay M, Balcik C, Kocak U (2016) Age estimation by assessing the vertebral osteophytes with the aid of 3D CT imaging. Aust J Forensic Sci Vol 49

9. Mays S, Cox M (2000) Sex determination in skeletal remains. Greenwich Medical Media Ltd, London, UK.

10. Torimitsu S, Makino Y, Saitoh H, Sakuma A, Iwase H, et al. (2016) Sexual determination based on multidetector computed tomographic measurements of the second cervical vertebra in a contemporary Japanese population. Forensic Sci Int 266: 588

11. Dawson B, Trapp R (2004) Basic and clinical biostatistics ( $4^{\text {th }}$ edn.). Mcgraw-Hill Inc, New York, USA.

12. Yu S, Lee U, Kwak D, Ahn W, Zhao J, et al. (2008) Determination of sex for the 12th thoracic vertebra by morphometry of three-dimensional reconstructed vertebral models. J Forensic Sci 53: 620-655.

13. Hou WB, Cheng KL, Tian SY, Lu YQ, Han Y, et al. (2012) Metric method for sex determination based on the 12th thoracic vertebra in contemporary north-easterners in China. J Forensic Leg Med 19: 137-143.

14. Jankauskas R (1994) Variability of vertebral column measurements in Lithuanian paleopopulation. Int J Anthropol 9:137-151.

15. Pastor RF (2005) Sexual dimorphism in vertebral dimensions at the T12/L1 junction. Proc J Forensic Sci 11: 302-303.

16. Gambaro L (2013) Sexual dimorphism of the thoracic vertebrae in a modern Cretan population: a comparison of the individual vertebrae in terms of accuracy in estimating sex. Bournemouth University, England, UK.

17. Torimitsu S, Makino Y, Saitoh, H, Sakuma A, Chiba F, et al. (2015) Stature estimation in Japanese cadavers based on pelvic measurements in threedimensional multidetector computed tomographic images. Int J Legal Med 129: 633-699.

18. Ramsthaler F, Kettner M, Gehl, A, Verhoff MA (2010) Digital forensic osteology: morphological sexing of skeletal remains using volumerendered cranial CT scans. Forensic Sci Int 195: 148-152.

19. Clavero A, Salicrú M, Turbón, D (2015) Sex prediction from the femur and hip bone using a sample of CT images from a Spanish population. Int J Legal Med 129: 373-383.

20. Zech WD, Hatch G, Siegenthaler L, Thali MJ, Losch S (2012) Sex determination from os sacrum by postmortem CT. Forensic Sci Int 221: 39-43.

21. Ruhli FJ, Muntener M, Henneberg M (2005) Age-dependent changes of the normal human spine during adulthood. Am J Phys Anthropol 17: 460-469.

22. Smith AK (2010) Aging of the lumbar vertebrae using known age and sex samples. Georgia State University, Georgia, USA.

23. Liguoro D, Vandermeersch B, Guérin J (1994) Dimensions of cervical vertebral bodies according to age and sex. Surgical and Radiologic Anatomy 16: 149-155.
24. Snodgrass J (2004) Sex differences and aging of the vertebral column. J Forensic Sci 49: 458-463.

25. Watanabe S, Terazawa K (2006) Age estimation from the degree of osteophyte formation of vertebral columns in Japanese. Leg med 8: 156-160.

26. Siemionow K, An H, Masuda K, Andersson G, Gunnar M, et al. (2011) The effects of age, sex, ethnicity, and spinal level on the rate of intervertebral disc degeneration: a review of 1712 intervertebral discs. Spine 36: 1333-1339.

27. Franchi L, Baccetti T, McNamara JA (2000) Mandibular growth as related to cervical vertebral maturation and body height. Am J Orthod Dentofacial Orthop 118: 335-340.

28. Baccetti T, Franchi L, McNamara JA (2002) An improved version of the cervical vertebral maturation (CVM) method for the assessment of mandibular growth. The Angle Orthodontist 72: 316-323.

29. Mito T, Sato K, Mitani H (2002) Cervical vertebral bone age in girls. Am J Orthod Dentofacial Orthop 122: 380-405.

30. Mito T, Sato K, Mitani H (2003) Predicting mandibular growth potential with cervical vertebral bone age. Am J Orthod Dentofacial Orthop 124: 173-177.

31. Baccetti T, Franchi L, Toffol L, Ghiozzi B (2006) The diagnostic performance of chronologic age in the assessment of skeletal maturity. Prog Orthod 7: 176-188.

32. Flores C, Burgess CA, Champney M, Jensen RJ, Pitcher M, et al. (2006) Correlation of skeletal maturation stages determined by cervical vertebrae and hand-wrist evaluations. Angle Orthod 76: 1-5.

33. Uysal T, Ramoglu SI, Basciftci FA, Sari, Z (2006) Chronologic age and skeletal maturation of the cervical vertebrae and hand-wrist: is there a relationship? Am J Orthod Dentofacial Orthop 130: 622-628.

34. Baidas L (2012) Correlation between cervical vertebrae morphology and chronological age in Saudi adolescents. King Saud University J Dental Sci 3: 21-26.

35. Baptista RS, Quaglio CL, Mourad L, Hummel AD, Augusto C, et al. (2012) A semi-automated method for bone age assessment using cervical vertebral maturation. The Angle Orthodontist 82: 658-662.

36. Alhadlaq M, Al-Maflehi NS (2013) New model for cervical vertebral bone age estimation in boys. J Dental Sci 4: 1-5.

37. Choi K, Kim J, Yamaguchi T, Maki K, Ko C, et al. (2016) Cervical Vertebral Body's Volume as a New Parameter for Predicting the Skeletal Maturation Stages. BioMed Research International pp: 1-7.

38. Taitz C (1996) Anatomical observations of the developmental and spondylotic cervical spinal canal in South African blacks and whites. Clin Anat 9: 395-400.

39. Ishikawa M, Matsumoto M, Fujimura Y, Chiba K, Toyama Y (2003) Changes of cervical spinal cord and cervical spinal canal with age in asymptomatic subjects. Spinal Cord 41: 159-163. 